\title{
From Micro to Macro: A New Methodology to Discriminate Among Models
}

\author{
Gee Hee Hong; Matthew Klepacz† Ernesto Pasten; and Raphael Schoenle ${ }^{\S}$ \\ This version: January 2019
}

\begin{abstract}
We propose a new methodology to discriminate among models that uses both micro and macro moments to discipline model choice. The key insight lies in using macro moments conditional on micro moments to discipline the response of the main variable of interest following a key policy shock. Some of the micro moments may be sufficient statistics. In an application to discriminate among leading price-setting models, Calvo and menu cost, we show that both Calvo and menu cost models match key micro price moments. However, only Calvo replicates the irrelevance of kurtosis for monetary non-neutrality following a monetary policy shock. Our menu cost model can match the irrelevance of kurtosis, but at the cost of missing key micro price moments.
\end{abstract}

JEL classification: E13, E31, E32

Keywords: Price-setting, Calvo pricing, menu cost, micro moments, sufficient statistics

*International Monetary Fund. e-Mail: GHong@imf.org

$\dagger$ College of William and Mary. e-Mail: mtklepacz@wm.edu

${ }^{\ddagger}$ Central Bank of Chile and Toulouse School of Economics. e-Mail: ernesto.pasten@tse-fr.eu

$\S$ Brandeis University. e-Mail: schoenle@brandeis.edu.

We thank Youngsung Chang, Olivier Coibion, Eduardo Engel, Emmanuel Farhi, Xavier Gabaix, and seminar participants at William and Mary and Seoul National University for helpful comments. Schoenle thanks Harvard University for hospitality during the preparation of this draft. 


\section{Introduction}

When a researcher writes down a new model, they usually face a big question: How should they discipline the parameters and behavior of the new model, and how should they decide whether to accept this model over existing models?

A widely popular approach for macro models in recent years has been the use of micro data. Micro data provides rich variation and therefore allows us to see if a candidate model is more successful than existing ones at hitting a larger set of target moments, in short, being more "realistic," while pinning down model parameters. When it comes to model selection, we usually accept a new candidate model when the model hits more, or more "relevant" micro moments than other models while implying different aggregate results. These results are understood to be the correct implications because the new model is more realistic. However, often prior beliefs and intuition guide us on which micro moments to use when we discipline and choose among models. If we chose different moments, conclusions might drastically differ. ${ }^{1}$ Which moments should we use?

This paper proposes a new methodology to systematically discriminate among models by using both micro and macro moments to discipline model choice. The key appeal lies in the complementary use of relevant macro moments to micro moments. Our methodology does so by taking two steps. First, we slice the micro data according to a moment considered into above and below-median bins, ${ }^{2}$ and calibrate a two-sector version of the model used by matching all micro moments in the bins to the two sectors. Second, we discriminate models by their ability to match across sectors the ordering across bins of empirical impulse responses to a policy shock for a macro variable of interest.

The novelty of our method lies in this second, non-parametric step. We link model discrimination directly to both the macro variable of interest and the micro moments. This approach empirically disciplines the main macro variable of interest in response to a

\footnotetext{
${ }^{1}$ The debate over the irrelevance of fixed costs for aggregate investment in the lumpy investment literature provides an illustrative example: For example, Khan and Thomas (2008) show that fixed costs are quantitatively irrelevant in a general equilibrium model when calibrating to establishment level investment rates, while Bachmann et al. (2013) argue that increasing the size of the fixed cost to empirically reasonable levels implies investment lumpiness is not inconsequential for macroeconomic analysis. The difference arises because Bachmann et al. (2013) instead use a calibration strategy that matches the volatility of aggregate and sectoral investment rates, and the ratio of the ninety-fifth and the fifth percentile of conditional heteroscedasticity in an $\mathrm{ARCH}$ model.

${ }^{2}$ We slice the data into only two bins and by one feature at a time in order to avoid small-sample error in the estimation of moments from micro data and a bias in the estimation of empirical impulse response functions when micro data changes infrequently (Berger et al. (2018)).
} 
key model shock while also jointly validating the choice of micro moments that pin down model parameters. Any model which does not match the ordered response of the macro variable across cuts of the micro data will not be valid for examining the policy change of interest. If both in the model and in the data, the ordered responses do not differ, then the micro moment considered is not informative with respect to the macro variable of interest. This rules out its potential sufficient statistic status, while the moment may of course still be informative in pinning down model parameters. ${ }^{3}$

To demonstrate the power of our methodology, we apply it to a long-standing question in macroeconomics: Which assumptions about price-setting behavior are relevant for the transmission of monetary policy shocks into the real economy? This question carries first-order importance because even small changes in modeling assumptions can have dramatic implications for the effects of monetary policy on the real economy. When it comes to making price-setting assumptions, one of the most prominent fault lines runs between two classes of models: whether price-setting is state-dependent, usually modeled as a menu cost model, or time-dependent, usually modeled as a Calvo model. We use our methodology to discriminate among these two leading models to demonstrate the relevance of our methodology.

This application further reveals an appealing feature of our approach for the policy-maker who aims at conducting counter-factual policy analysis: Our approach is good at describing dynamics conditional on a small, specific shock in normal times. By contrast, model choice in practice that employs micro data is often made by requiring models to fit during particular, exceptional episodes - unconditionally on a shock. This contrast certainly holds true for our application: Gagnon (2009) evaluate the performance of Calvo versus menu costs for the Tequila crisis in Mexico, Alvarez et al. (2019) during hyperinflation in Argentina, Nakamura et al. (2018) for the Great Inflation in the U.S. in the 1970s, or Karadi and Reiff (2018) for VAT changes in Hungary. While these papers find that a menu cost model is a better fit to unconditional inflation dynamics in such exceptional episodes, we find that an enriched Calvo model is a better description of inflation dynamics conditional on a small monetary policy shock in normal times.

Empirically, we find that a lower frequency of price changes is related to larger consumption responses. Kurtosis of price changes is not a sufficient statistic for the

\footnotetext{
${ }^{3}$ The ability of our methodology to test sufficiency of proposed sufficient statistics is a very important aspect of our methodology.
} 
real effects of monetary shocks, but as a derivative, kurtosis over frequency is. When we compare these empirical, conditional impulse responses to their theoretical counterparts, both Calvo and menu cost models match the impulse response ordering according to frequency and kurtosis over frequency cuts of the data. However, only Calvo replicates the irrelevance of kurtosis, while a menu cost model runs into problems. In a menu cost model kurtosis is not a sufficient statistic for monetary non-neutrality, and kurtosis over frequency is not sufficient unless it varies one-to-one with frequency. Our menu cost model can match the irrelevance of kurtosis - but this comes at the cost of missing moments in the first step of our methodology.

Overall, we conclude a Calvo model is more suitable to counterfactual policy analysis regarding the real effects of monetary shocks, rather than a menu cost model. To be clear, we are not arguing that firms actually price goods following the Calvo model. In this sense, we endorse the argument by Eichenbaum (2018a) that models of nominal price rigidity should not be taken literally but rather as an approximation of the effect of monetary policy shocks on the actual pricing decision process of firms. ${ }^{4}$

Our analysis arrives at these results in three steps. First, we apply the first step of our methodology and use micro data to establish empirical impulse response functions. In particular, we use the micro price data that underlie the producer price index (PPI) at the Bureau of Labor Statistics (BLS) to classify the PPI inflation data published at the NAICS six-digit level into two subsets: one subset above, and the other below the median of a proposed sufficient statistic. For these sufficient statistics, we consider the frequency of price changes, kurtosis of the distribution of price changes, and the ratio of frequency over kurtosis. Next, we compute a weighted index of PPI inflation for each subset. We then use these indices to compute impulse response functions in response to a monetary policy shock. We use two alternative methods to compute response functions, respectively using the FAVAR approach as in Bernanke et al. (2005), and the Romer and Romer (2000) identification strategy of monetary policy shocks.

Both identification schemes show that inflation is more responsive to monetary policy shocks for the index made up of sectors with above-median frequency of price changes than

\footnotetext{
${ }^{4}$ As Eichenbaum (2018b) argues, the clear disadvantage of the Calvo model relative to the menu cost model of predicting unrealistic long spells of few prices makes it non-suitable for welfare analysis, but such a disadvantage may not invalidate its implications for aggregate dynamics in response to monetary policy shocks.
} 
the index made up by sectors with below-median frequency. However, the responsiveness of both indices sorted by kurtosis is almost identical. Since inflation is more responsive for the below-median kurtosis over frequency index than the above-median kurtosis over frequency index, we conclude that kurtosis over frequency is a sufficient statistic for monetary non-neutrality only because frequency is.

Second, we demonstrate how our proposed methodology discriminates among models. As a prelude, we establish that kurtosis is not a sufficient statistic for monetary non-neutrality even in a stylized, single-sector menu cost model. This prelude illustrates the tension emanating from impulse response comparisons that give bite to our two-step methodology. To arrive at the result, we calibrate the model to match exactly the same CPI moments as in Vavra (2014). We then vary them to understand what pricing moments are relevant for monetary non-neutrality. We find that increasing frequency of price adjustment while holding all other moments fixed lowers monetary non-neutrality. Examining the relevance of kurtosis over frequency, we lower kurtosis while holding frequency fixed and find that monetary non-neutrality increases as kurtosis falls. This finding stands in contrast to the prediction of Alvarez et al. (2016).

Next, as our main step, we use state-of-the-art multi-sector menu cost and Calvo models to demonstrate the complete model-discrimination step. We compare the two models of price-setting in three economies, each with two sectors. Each economy corresponds to one of the three empirical slicings of sectors according to the frequency of price change, kurtosis of the distribution of price changes, or the ratio of kurtosis over frequency. In each economy, we calibrate one model sector to be representative of the average price-setting moments in sectors above the median of the respective sufficient statistic, and one sector to moments in sectors below the median. We target the following price-setting moments: frequency of price changes, average absolute size of price changes, the fraction of price changes less than one percent, kurtosis, and kurtosis over frequency.

Crucially, we now also obtain impulse response functions of prices for each of the two sectors in each of the three economies, and by price-setting model. We compare the ordering of these impulse responses to their empirical analogues for each model of price-setting. This approach encompasses the conventional matching of micro pricing moments, but then further disciplines the model using the actual responses to a monetary shock. 
We find that our multi-sector menu cost model runs into difficulties. The menu cost model successfully replicates the impulse response ordering of frequency as well as kurtosis over frequency. However the menu cost model implies large differences in price responses across sectors to a monetary shock when we split them by kurtosis, contradicting our main empirical result. By contrast, the multi-sector Calvo model successfully matches the impulse response ordering when the sectors are split by frequency, kurtosis over frequency, and kurtosis.

Third, we show that our menu cost model can match the empirical irrelevance of kurtosis - but this comes at the cost of missing micro moments in the first step of our methodology. We show this result by first calibrating a menu cost model to the exact moments from the data. We then consider model parameters one at a time. Holding all other parameters at their calibrated values, we find the parameter values in the two sectors such that we match the irrelevance of kurtosis. We generally find that it is possible to match the irrelevance of kurtosis with the right combination of parameter values in the two sectors, but this comes at the cost of missing some of the other moments.

We organize the paper as follows: Section II discusses our new proposed methodology and our data. Section III establishes the empirical regularities that compare impulse response functions across different values of micro moments. Section IV presents the modeling setup. Section V demonstrates how we discriminate across models, and Section VI concludes.

\section{A. Literature review}

Our paper makes two contributions to the literature. On the one hand, our methodology provides guidance for the use of micro data in macro modeling. It may have even broader applicability beyond the setting we describe here. On the other hand, our methodology contributes by providing new insights to the long-standing question in macroeconomics on which price-setting assumptions are key to the transmission of monetary policy shocks. We build on an existing literature which is too wide to discuss in detail. However, our analysis connects to several important recent papers.

First, our paper contributes by suggesting a new, more refined methodology of model selection to the literature. The commonly used approach that exploits micro moments follows the notion that, by matching certain new or more relevant micro moments, we 
are matching the data better overall, and the new proposed model must be closer to the truth. We present a methodology that adds a second, simple model discrimination step - comparing theoretical conditional impulse response orderings to their empirical analog - to make the inference of model fit more rigorous. This idea is related to the indirect inference method of Smith (1993) and Gourieroux et al. (1993) who suggest using an auxiliary model such as a VAR to form a criterion function. We are suggesting to make use of the ordering and the distance between sectoral impulse response functions to discriminate among models.

By adding this step, our methodology also speaks directly to the recent studies on sufficient statistics approach. This approach proposes universal sufficient statistics to fully pin down monetary non-neutrality, an explicitly more comprehensive claim than the implicit approach described above. The approach has recently been pioneered by the important theoretical contribution by Alvarez, Le Bihan and Lippi (2016). This paper establishes that across a large class of models, frequency and kurtosis are two key determinants of monetary non-neutrality, while we know that frequency is the sole determinant in the Calvo model. Our main relative contribution is to provide empirical impulse response functions in samples split along different values of these sufficient statistics. These empirical impulse response functions allow us to evaluate whether this sufficient statistics approach is indeed sufficient with respect to empirically measured monetary non-neutrality. We show that empirically only frequency matters.

Moreover, we also relate to the recent literature that shows that conventional sufficient statistics may not even theoretically be sufficient to discriminate models. Dotsey and Wolman (2018) and Karadi and Reiff (2018) analyze sophisticated menu costs models to make such arguments. We show that even in a simple menu cost model, calibrated to CPI micro moments, one specific sufficient statistic, kurtosis of price changes, is not a sufficient statistic - if we also want to match the empirical impulse response ordering following monetary policy shocks.

To arrive at our results, our model setup builds on advances by several papers that have pushed the modeling frontier. Building off of the model of Golosov and Lucas (2007), work by Midrigan (2011) showed that menu cost models can generate large real effects. Key to this result is a multi-product setting where small price changes take place, as well as leptokurtic firm productivity shocks which generate large price changes. Nakamura and 
Steinsson (2010) have further developed a Calvo-plus model featuring occasional nearly free price changes. This modeling trick generates price changes in the Calvo setting similar to a multi-product menu cost model. Our model setup takes into account these advances in modeling assumptions.

While our methodology proposes a non-parametric second step, a trivial extension would also to match the particular shapes of the impulse response functions. We explicitly allow for it in an extension of our methodology. Our illustrative example, however, does not match impulse response functions. Such an exercise would require adding a number of features to the model to replicate inertial and hump-shaped behavior of aggregate inflation and quantities, as stressed by Christiano et al. (2005). Adding these features is not necessary to make our point: Our methodology to discern models only requires to replicate the relative behavior of impulse responses as moments vary. In the case of our illustrative example, we are already able to discriminate between Calvo and menu cost models based on this simple non-parametric approach.

We also contribute to the large and growing literature that studies the heterogeneous response to monetary shocks. Cravino et al. (2018) is closest to our work, who empirically show that high-income households consume goods which have stickier, and less volatile prices than middle-income households. Kim (2016) presents related results.

\section{Methodology}

This section presents a novel approach for researchers to discriminate among models. We first illustrate the conventional approach of evaluating model B relative to existing model A, where model $\mathrm{B}$ is a candidate "improved" model. We then contrast that approach with our proposed methodology.

Our methodology has two steps. The first step absorbs conventional micro moment matching. The second step complements the first by combining the use of micro and macro moments and considering macro moments, conditional on micro data. This combination is meaningful because macro moments are an object of interest by themselves. They allow us to understand which micro moments are informative for modeling and can contribute to model selection with the "big picture" in mind.

The innovation in our approach is conceptual, and lies in the combination of statistical 
and modeling techniques. While they are individually frequently used, combined together they may have important implications when working with micro data. Therefore, our description below emphasizes the conceptual steps, but mainly leaves statistical details to standard textbooks.

\section{A. Conventional Approach}

By "conventional" approach, to which we contrast our methodology, we understand one in which a researcher matches a vector of moments from the micro data. These moments pin down model parameters, and the simulated method of moments (SMM) embodies this approach of matching moments. When it comes to model selection, the "conventional" approach accepts a new candidate model that matches more relevant or a larger number of micro moments while also implying different aggregate results.

The motivation for using micro data in this approach - which has become widely used in practice and which is our focus - is the direct result of micro-founding models. Micro data opens up new variation in the data to discipline choices of micro-founded models and makes models more realistic descriptions of the economy. Aggregate data may often not deliver such necessary variation.

Consider the following, general structure as a basis mathematical description of the approach:

$$
Y_{t}=H\left(Y_{t-1}, C, \epsilon_{t}, \eta_{t}, \Theta\right)
$$

where $Y_{t}$ denotes the model variables, which may include expectations. The function $H$ describes the potentially non-linear evolution of the model as a function of lagged variables. $C$ denotes a constant, $\epsilon_{t}$ exogenous shocks, $\eta_{t}$ endogenous expectational errors and $\Theta$ a set of model of $p$ parameters. A linear rational expectations example of this system is given by Sims (2002).

While many approaches exist to solve and estimate such systems, ${ }^{5}$ matching micro moments from the data to pin down the parameters that govern the model is a common

\footnotetext{
${ }^{5}$ For example, Bayesian estimation or maximum likelihood estimation are other popular approaches to estimate models. However, they are not more common when it comes to exploiting the variation in micro data because they are difficult to implement. The difficulty lies both in the computational constraints and the difficulty of writing down the likelihood function. Recent advances in the heterogeneous agent literature such as Winberry (2018) partially address these constraints using the Reiter (2009) method which facilitates computation in a linearized system.
} 
approach we consider as our benchmark of interest. Model simulation can generate the moments to match the data, even if no closed form moment expressions exist (see McFadden (1989)). Following the approach, the researcher uses simulated method of moments to obtain the best fitting parameters $\hat{\Theta}$ :

$$
\hat{\Theta}=\arg \min (\Psi-\hat{\Psi}(\Theta))^{\prime} W_{N}(\Psi-\hat{\Psi}(\Theta))
$$

where $\Psi$ denotes a vector of micro moments from the data with $N$ observations, $\hat{\Psi}$ a vector of simulated moments from the model with $S$ simulations, and $W_{N}$ is an optimal weighting matrix, which may be a function of $N$, the number of sample observations. The overidentifying test of the model converges to

$$
\frac{N S}{1+S} \hat{\Theta} \sim \chi^{2}(q-p)
$$

where $\mathrm{q}$ is the number of moments and $\mathrm{p}$ is the number of parameters. For example, one such moment could be the frequency of price adjustment. Note that moments may or may not be sufficient statistics.

How can we use this conventional approach to discriminate among models? Suppose we consider a new candidate model, model B. Without loss of generality, assume this model contains one new, additional parameter. To pin down the given new parameter, the researcher adds a moment to the set of moments he matches. Denote the new parameter estimates by $\hat{\Theta}_{B}$ as opposed to $\hat{\Theta}_{A}$ from benchmark model A. Ideally, the proposed model $\mathrm{B}$ succeeds in matching the new moment in addition to the existing moments while the existing model A fails in hitting the new target. One can equally consider the case when we simply examine a model $\mathrm{B}$ with an alternative set of moments, but the same number of moments as model A. The moment of interest does not have to be a new moment, or among any new moments. The next step in model discrimination equally applies.

When do we accept model B over model A? Researchers usually proceed to show that the potentially new moment of interest is economically important because simulations of model B imply stark differences in some key variable of interest, generically captured by vector element $Y_{i}$. For example, the difference can lie in cumulative aggregate real output effects $\zeta^{i}$ with $i \in A, B$, following a monetary policy shock $\epsilon_{t}^{M}$ : 


$$
\zeta^{B}=\sum_{j} \partial Y_{i t+j}^{B} / \partial \epsilon_{t}^{M}
$$

which differs from

$$
\zeta^{A}=\sum_{j} \partial Y_{i t+j}^{A} / \partial \epsilon_{t}^{M}
$$

Given large differences between $\zeta^{B}$ and $\zeta^{A}$, model B is usually considered to have new, important implications. The usual discrimination exercise stops here because model $\mathrm{B}$ is thought to have more realistic implications.

However, in principle, one could continue searching for models and matching moments that continue to modify conclusions of which model elements matter and which moments discipline models. In fact, Klenow and Malin (2011) suggest that one can always find a new moment that will lead us to reject an existing model. And often, this is how progress is made.

One approach to direct and potentially stop this search process is the sufficient statistic approach. This approach tries to answer what aspects of microeconomic heterogeneity matter for a macroeconomic model. The approach picks an outcome variable commonly accepted to be of interest - such as monetary non-neutrality - and describes the moments that, once matched, will sufficiently pin down the outcome variable of interest. No other moments should be informative for the variable of interest. These sufficient statistics are usually derived from widely general classes of models. Alvarez et al. (2016) presents an elegant recent example of this sufficient statistics approach for monetary non-neutrality.

These sufficient statistics usually also relate to micro modeling aspects. Naturally, their empirical counterparts necessarily lie in the micro data. At the same time, the sufficient statistics approach also has a key problem: It is based on the assumption that we know the true, widely general model that pins down our variable of interest such as monetary non-neutrality. Therefore, considering the implied sufficient statistics, in particular, the associated micro moments, may not be "sufficient enough." 


\section{B. Our Novel Micro-Macro Approach}

Our proposal to strengthen the "conventional" approach lies in systematically using macro data to discipline the model response of the chosen macro variable of interest following a model-specified shock. At the same time, the approach requires the researcher to continue to jointly match micro moments from the data to build a realistic micro-founded model.

Consider again a researcher who wants to apply SMM to pin down a parameter $\theta_{j}$ using a particular moment $\Psi_{j}$. The researcher may be comparing a new model B to an existing, simpler model A in which case he is adding a new moment. Or he may believe he has found a more informative moment $\Psi_{j}$ he would like to use. Note this target moment need not be the newly added moment at all, and it may or may not be a sufficient statistic, as before. If it is, it has a very high information content for its object of sufficiency. In either case, the researcher's ultimate object of interest is again the behavior of some macroeconomic aggregate $\left\{Y_{i, t}\right\}$ following some shock in the model, $\epsilon^{M}$. In the following we compare, without loss of generality, a new richer model B to an existing model A.

As a first step, our methodology absorbs the "conventional" methodology, but gives it a new twist. The twist lies both on the theoretical and the empirical side. On the empirical side, we use the micro nature of the data to split the data into two: We sort the data into an above-median and a below-median dataset according to the distribution of observation-specific moments $\left\{\Psi_{j, k}\right\}_{k=1}^{N}$ given particular moment of interest $\Psi_{j}$ and units of observations $\mathrm{k}$ such as firms or sectors (for example, this moment could be the sector-specific frequency of price changes). Denote the above-median sector by $H$, the below-median sector by $L$. We compute a complete set of micro moments in each dataset, $\Psi_{H}$ and $\Psi_{L}$. This split of the data is needed only once for the moment under consideration (whether in a richer model B or a simply in a model A with a different new moment) but the computation of moments needs to be done for each model under consideration since the models may differ.

Next, on the theoretical side, we create a two-sector setting of the respective model. We choose parameters in each of its sectors to match the micro moments in each dataset, in each model, thus omitting superscripts A and B:

$$
\left[\begin{array}{c}
\hat{\Theta}_{H} \\
\hat{\Theta}_{L}
\end{array}\right]=\arg \min \left[\begin{array}{c}
\Psi_{H}-\hat{\Psi}_{H}\left(\Theta_{H}\right) \\
\Psi_{L}-\hat{\Psi}_{L}\left(\Theta_{L}\right)
\end{array}\right]^{\prime} W\left[\begin{array}{c}
\Psi_{H}-\hat{\Psi}_{H}\left(\Theta_{H}\right) \\
\Psi_{L}-\hat{\Psi}_{L}\left(\Theta_{L}\right)
\end{array}\right]
$$


Our new, second step brings in macro data to discipline the model choice non-parametrically. Given the researcher's variable of interest is macroeconomic aggregate $\left\{Y_{i, t}\right\}$, the natural choice to do so is to use the empirical response of sectoral aggregates $\left\{Y_{H, i, t}\right\}$ and $\left\{Y_{L, i, t}\right\}$ to some shock of interest in both models, $\epsilon^{M}$. For our approach, it does not matter how one obtains the empirical estimates of $\left\{Y_{H, i, t}\right\}$ and $\left\{Y_{L, i, t}\right\}$. For example, they can be from a FAVAR, a VAR or derived from a narrative technique.

Compared to the "conventional approach," when do we now decide to accept model B over model A? First, we use the two-sector model to generate model-equivalent series of the variables of interest, $\left\{\hat{Y}_{H, i, t}\right\}$ and $\left\{\hat{Y}_{L, i, t}\right\}$. Next, we non-parametrically compare the model-generated impulse response functions $\left\{\hat{Y}_{H, i, t}\right\}$ and $\left\{\hat{Y}_{L, i, t}\right\}$ to their data counterparts $\left\{Y_{H, i, t}\right\}$ and $\left\{Y_{L, i, t}\right\}$. Our decision is to accept the new model and choice of micro moments if the response ordering in the model - given variation in the micro moment $\Psi_{j}-$ and the response ordering in the data - given variation in the empirical micro moment $\Psi_{j}$ - are identical for model $\mathrm{B}$, but not for model A:

That is, if an increase in $\Psi$ from $\Psi_{L}^{B}$ to $\Psi_{H}^{B}$ in model B, associated with a ranking

$$
\left\{\hat{Y}_{H, i, t}^{B}\right\}>\left\{\hat{Y}_{L, i, t}^{B}\right\} \forall t
$$

matches the ranking in the data, given the split of the micro data according to $\Psi_{H}>$ $\operatorname{median}\left(\Psi_{i}\right)>\Psi_{L}$ :

$$
\left\{Y_{H, i, t}\right\}>\left\{Y_{L, i, t}\right\} \forall t
$$

then we accept model B over model A, which shows an opposite response ordering $\left\{\hat{Y}_{H, i, t}^{A}\right\}<\left\{\hat{Y}_{L, i, t}^{A}\right\}$, or a non-informative response ordering $\left\{\hat{Y}_{H, i, t}^{A}\right\}=\left\{\hat{Y}_{L, i, t}^{A}\right\}$. Note that without loss of generality, the response ordering in the data may be flipped given the split of the micro data. The requirement on the model response ordering then flips accordingly.

\section{Methodology Refinements}

This section presents three refinements of our methodology. First, we show how one can evaluate model fit more quantitatively. Second, we present an explicit approach to deal with time-varying moments. Finally, we show how the procedure can be extended to evaluate models when more than one micro moment is of interest. 


\section{C.1 Quantitative Refinements}

A trivial extension of our methodology lies in a more quantitative evaluation of the impulse response functions for the macro variable of interest. This extension goes beyond the simple non-parametric test of model fit which we have added as a key ingredient in our second step. It may come at a computational cost but allows us to match the particular shapes of the impulse response functions. In terms of implementation, this extension simply includes $Y_{L}$ and $Y_{H}$ as targets into the moments in equation (6) for each model. That is:

$$
\left[\begin{array}{c}
\hat{\Theta}_{H} \\
\hat{\Theta}_{L}
\end{array}\right]=\arg \min \left[\begin{array}{c}
\Psi_{H}-\hat{\Psi}_{H}\left(\Theta_{H}\right) \\
Y_{H}-\hat{Y}_{H}\left(\Theta_{H}\right) \\
\Psi_{L}-\hat{\Psi}_{L}\left(\Theta_{L}\right) \\
Y_{L}-\hat{Y}_{L}\left(\Theta_{L}\right)
\end{array}\right]^{\prime} W\left[\begin{array}{c}
\Psi_{H}-\hat{\Psi}_{H}\left(\Theta_{H}\right) \\
Y_{H}-\hat{Y}_{H}\left(\Theta_{H}\right) \\
\Psi_{L}-\hat{\Psi}_{L}\left(\Theta_{L}\right) \\
Y_{L}-\hat{Y}_{L}\left(\Theta_{L}\right)
\end{array}\right]
$$

We view this extension as a complementary or possible third step.

\section{C.2 Accounting for Time-Variation in Moments}

Our methodology can also be extended to account for time variation in a model moment of interest. For example, suppose a moment is a function of the business cycle regime, an "expansion" and a "recession," and this dependence causes the response of the variable of interest to be state-dependent. Denote expansions by $E$ and recessions by $R$. For each regime, calculate moments of interest in the data, $\Psi_{H, E}, \Psi_{H, R}, \Psi_{L, E}$, and $\Psi_{L, R}$, as well as the response in the variable of interest, $\left\{Y_{H, i, t, E}\right\},\left\{Y_{H, i, t, R}\right\},\left\{Y_{L, i, t, E}\right\}$, and $\left\{Y_{L, i, t, R}\right\}$. The response can be calculated using a regime switching VAR, or other methods.

In a first step, the model must match micro moments in both regimes:

$$
\left[\begin{array}{c}
\hat{\Theta}_{H} \\
\hat{\Theta}_{L}
\end{array}\right]=\arg \min \left[\begin{array}{c}
\Psi_{H, E}-\hat{\Psi}_{H, E}\left(\Theta_{H}\right) \\
\Psi_{H, R}-\hat{\Psi}_{H, R}\left(\Theta_{H}\right) \\
\Psi_{L, E}-\hat{\Psi}_{L, E}\left(\Theta_{L}\right) \\
\Psi_{L, R}-\hat{\Psi}_{L, R}\left(\Theta_{L}\right)
\end{array}\right]^{\prime} W\left[\begin{array}{c}
\Psi_{H, E}-\hat{\Psi}_{H, E}\left(\Theta_{H}\right) \\
\Psi_{H, R}-\hat{\Psi}_{H, R}\left(\Theta_{H}\right) \\
\Psi_{L, E}-\hat{\Psi}_{L, E}\left(\Theta_{L}\right) \\
\Psi_{L, R}-\hat{\Psi}_{L, R}\left(\Theta_{L}\right)
\end{array}\right]
$$

In a second step, after the regime-specific moments are matched, the model-generated variables of interest are compared to their empirical counterparts. The ordering in both the expansion regime, 


$$
\left\{\hat{Y}_{H, i, t, E}\right\}>\left\{\hat{Y}_{L, i, t, E}\right\} \forall t
$$

and recession regime,

$$
\left\{\hat{Y}_{H, i, t, R}\right\}>\left\{\hat{Y}_{L, i, t, R}\right\} \forall t
$$

is informative for model selection. We now accept the new model if both rankings match. Because two sets of impulse responses have to fit the ordering to reach acceptance of a new model, this criterion is stricter than the previous single-regime criterion.

Again, a further extension may lie in a more quantitative evaluation of the impulse response functions for the macro variable of interest, as outlined above, but now jointly across regimes.

\section{C.3 Multiple Moments of Interest}

The methodology is now extended to allow a macro moment of interest to jointly depend on more than one moment. Suppose a researcher believes that two new micro moments jointly affect the macro moment of interest. That is, the value of the moments $\Psi_{1}$ and $\Psi_{2}$, affect the response of $Y_{i, t}$.

The first step is to split the data into four groups. The micro data is first separated into above-median and below-median values for one of the two micro moments, then each half of the data is split into above-median and below-median values of each subset for the second micro moment. The micro moments are denoted by $\Psi_{H H}, \Psi_{H L}, \Psi_{L H}$, and $\Psi_{L L}$ where the first subscript indexes moment $\Psi_{1}$ and the second subscript indexes moment $\Psi_{2} \cdot{ }^{6}$

The second step is to construct a four-sector setting of the respective model. Each sector has it's parameters chosen to match the micro moments in each dataset, where the four groups are constructed as described above. Micro moments are matched as follows:

\footnotetext{
${ }^{6}$ If we assume that the two moments are conditionally independent of each other, then the four groups will be the same in expectation. Additionally, reversing the ordering of the classification and comparing the resulting groupings will give a measure of the dependence of the two moments. The interaction of the two micro moments, a continuous measure, can also be used to classify groups.
} 


$$
\left[\begin{array}{c}
\hat{\Theta}_{H H} \\
\hat{\Theta}_{H L} \\
\hat{\Theta}_{L H} \\
\hat{\Theta}_{L L}
\end{array}\right]=\arg \min \left[\begin{array}{c}
\Psi_{H H}-\hat{\Psi}_{H H}\left(\Theta_{H H}\right) \\
\Psi_{H L}-\hat{\Psi}_{H L}\left(\Theta_{H L}\right) \\
\Psi_{L H}-\hat{\Psi}_{L H}\left(\Theta_{L H}\right) \\
\Psi_{L L}-\hat{\Psi}_{L L}\left(\Theta_{L L}\right)
\end{array}\right]^{\prime} W\left[\begin{array}{c}
\Psi_{H H}-\hat{\Psi}_{H H}\left(\Theta_{H H}\right) \\
\Psi_{H L}-\hat{\Psi}_{H L}\left(\Theta_{H L}\right) \\
\Psi_{L H}-\hat{\Psi}_{L H}\left(\Theta_{L H}\right) \\
\Psi_{L L}-\hat{\Psi}_{L L}\left(\Theta_{L L}\right)
\end{array}\right]
$$

The final step of the procedure is to compare the model generated impulse response function to their empirical equivalent. Examining multiple moments at a time is more stringent because there are more potential orderings of responses. The model selection step consists of the comparison of the macro moment of interest across all sectors:

$$
\left\{\hat{Y}_{H H, i, t}\right\}>\left\{\hat{Y}_{H L, i, t}\right\}>\left\{\hat{Y}_{L H, i, t}\right\}>\left\{\hat{Y}_{L L, i, t}\right\} \forall t
$$

and comparing it to the ranking in the data

$$
\left\{Y_{H H, i, t}\right\}>\left\{Y_{H L, i, t}\right\}>\left\{Y_{L H, i, t}\right\}>\left\{Y_{L L, i, t}\right\} \forall t
$$

where the ordering in the data can switch without loss of generality. If the new model successfully matches the ordering of response while the old model shows the opposite or non-informative response ordering, the new model is accepted. This procedure can further be generalized to more than two moments by adding additional subsets of the data.

\section{Application: Calvo vs. Menu Cost}

It is a long-standing question in macroeconomics which assumptions about price-setting behavior are key to the transmission of monetary policy shocks into the real economy. This question carries first-order importance because even small changes in modeling assumptions can have dramatic implications for the effects of monetary policy on the real economy. When it comes to making price-setting assumptions, one of the most prominent fault lines runs between two classes of models: whether price-setting is state-dependent, usually modeled as a menu cost model, or time-dependent, usually modeled as a Calvo model.

This section focuses on an application of our proposed methodology to discriminate state-of-the-art Calvo from menu cost models. As a test case for our new methodology, 
we consider a sufficient statistic description of the two models. For the Calvo model, this is the frequency of price changes. For the menu cost model, we additionally consider the kurtosis of price changes and the ratio of kurtosis over frequency, following Alvarez et al. (2016) example of sufficient statistics for monetary non-neutrality. Otherwise, we use identical micro moments to pin down model parameters. Our key variable of interest is monetary non-neutrality following a monetary policy shock.

In line with our new approach, we first establish a macro moment for our key variable of interest in the data. We generate empirical impulse response functions of aggregate inflation following a monetary policy shock, using two independent methodologies. In accordance with our methodology, we generate these impulse responses for both high and low levels of the moments - here: also sufficient statistics - which we consider one at a time: frequency, kurtosis and kurtosis over frequency of price changes. Then, we use a number of micro price moments to calibrate two-sector versions of the two models. We compare the theoretical impulse response ordering to the one from the data.

Since the last step requires us to have empirical impulse response functions conditional on sufficient statistics, we first describe the two ways we generate them.

\section{A. Empirical Responses to Monetary Shocks: FAVAR}

Our first approach to obtain impulse response functions in the different cuts of the data follows the factor-augmented vector autoregressive model (FAVAR) in Boivin et al. (2009). In this first approach, we identify the monetary policy shock with a federal funds rate shock that drives the impulse responses. We refer the reader for details of the FAVAR approach to Boivin et al. (2009). The appeal of the FAVAR lies in drawing from a large set of variables containing information of (slow-moving) macro variables and (fast-moving) financial variables, enabling us to better identify policy shocks than standard VARs.

The data used in the estimation of the FAVAR exercise is the same set of various macroeconomic indicators and financial variables used in Boivin et al. (2009). Some examples of the macroeconomic indicators included in the data set are several measures of industrial production, interest rates, employment and various aggregate price indices. The data set is a balanced panel of 653 monthly series, spanning 353 months from January 1976 to June 2005. As in Boivin et al. (2009), we transform each series to ensure stationarity.

We also include disaggregated data on personal consumption expenditure (PCE) 
series published by the Bureau of Economic Analysis, consistent with Boivin et al. (2009). Due to missing observations, we remove 35 real consumption series and are left with 194 disaggregated PCE price series.

How do we use the FAVAR to obtain the impulse responses in the cuts of the data that are characterized by above-median and below-median moments? We have chosen as our variable of interest the inflationary response of the economy. Therefore, we first use the FAVAR to generate PPI inflationary responses $\pi_{k, t}$ for each sector $k$ :

$$
\pi_{k, t}=\lambda_{k} C_{t}+e_{k, t}
$$

In the FAVAR setting, this sectoral inflationary response is given by the loading $\lambda_{k}$ on the VAR evolution of the common component $C_{t}$. This component in turn includes the evolution of the federal funds rate which we shock. There are 154 such sector-level producer price (PPI) series in the FAVAR data.

Then, we sort these 154 sectors into an above-median and below-median bin according to these three moments of interest: Frequency of price changes, kurtosis of price changes or kurtosis over frequency. This requires us to have sectoral price-setting statistics. We obtain them by additionally exploiting the underlying micro price data from the PPI. For each of the corresponding 154 series, we construct sectoral level price statistics using PPI micro data from 1998 to 2005. We compute pricing moments at the good level, and then take averages at the respective six-digit NAICS industry level, each of which corresponds to one of the 154 series. We then assign sectors into above-median and below-median bins for any given moment of interest.

Finally, we compute the mean of the $\left\{\pi_{k, t}\right\}$ - the inflationary responses following a monetary policy shock - in the two subsets of the data characterized as above-median and below-median according to each moment of interest. These series embody the response of inflation following a monetary policy shock, conditional on high and low levels of micro moments.

\section{B. Empirical Response to Romer and Romer Shocks}

As a second approach to identify the effect of monetary policy shocks, we follow the narrative approach in Romer and Romer (2004). The original Romer and Romer (2004) 
monetary policy shocks are calculated as residuals from a regression of the federal funds rate on its lagged values and the information set of Federal Reserve Greenbook forecasts. The original series is available from January 1969 to 1996. Using the same methodology, Wieland and Yang (2017) have extended the series up to December 2007. We use monthly PPI inflation data from January 1969 to December 2007.

To obtain the inflationary response in the data according to high or low sufficient statistic, we estimate the following regression specification:

$$
\pi_{t}^{c}=\alpha^{c}+\sum_{k=1}^{11} \beta_{k}^{c} D_{k}+\sum_{k=1}^{24} \gamma_{k}^{c} \pi_{t-k}^{c}+\sum_{k=1}^{48} \theta_{k}^{c} M P_{t-k}+\epsilon_{t}^{c}
$$

where $\mathrm{c}$ is an indicator for either the above-median or below-median industry according to the sufficient statistic under consideration. The same statistics are examined as in the FAVAR analysis. $M P_{t-k}$ refers to the extended Romer and Romer monetary shock series. The inflation series $\pi_{t}^{c}$ are the average PPI inflation rates in the high or low subsets of the same data described above for the FAVAR. $D_{k}$ denotes monthly fixed effects to control for seasonality. We estimate coefficients for the two subsets of data separately to allow for differential coefficients on lagged inflation as well as the monetary shock.

To estimate the differential inflationary responses following a monetary policy shock, we run each regression separately for the average industry inflation rate above and below the median value of the proposed statistic. We construct above-median and below-median industry statistics using the PPI micro data as described in the above section. Following the estimation of the above specification, the estimated impulse response of interest is contained in the parameter estimates of $\theta_{k}$. For example, the inflationary response after one month is just $\theta_{1}$ for any given subset of data for a proposed statistic.

\section{Empirical Regularities}

In this section, we present the empirical impulse response functions generated by the two different methodologies discussed above. The impulse responses provide empirical validation on whether or not certain model micro moments are indeed sufficient statistics for monetary non-neutrality.

As our main result, we find that among the model micro moments we consider motivated by the sufficient statistics approach in Alvarez et al. (2016) - frequency of 


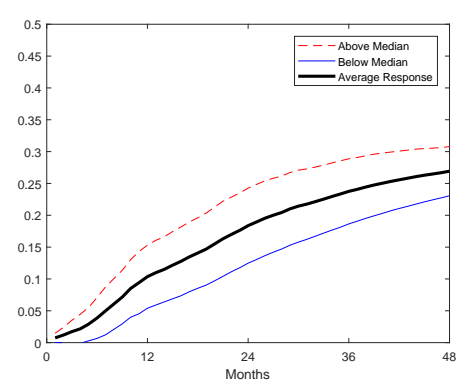

a Frequency

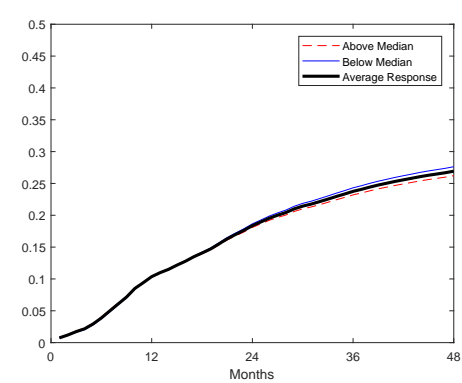

b Kurtosis

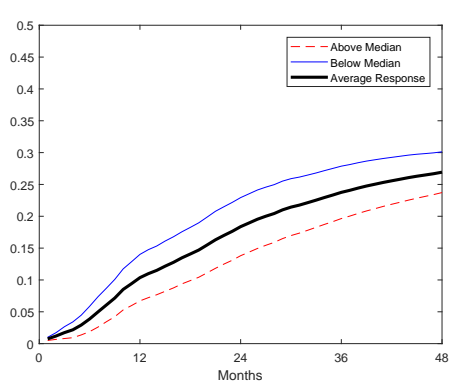

c Kurtosis/Frequency

Figure 1: FAVAR Monetary Policy Shock IRF of Inflation

Note: In all three figures, "Above Median" and "Below Median" refer to the impulse response function of industries whose pricing moment is above or below the median value of that statistic for all industries. Estimated impulse responses of sectoral prices in percent to an identified 25 basis point unexpected Federal Funds rate decrease are shown.

price changes is the only moment that generates a meaningful difference in the price response to monetary shocks. In turn, kurtosis over frequency generates similar results, although the result is driven by frequency of price changes and not by kurtosis.

The FAVAR implied impulse response to a surprise 25 basis point decrease in the federal funds rate is shown in Figure 1. Consistent with our expectations, the average impulse response function of the high frequency group shows a larger response to monetary shock than low frequency bin, implying smaller real effects of monetary policy. This confirms the key assumption of all sticky price models.

When we split industries by their kurtosis of price changes, however, we do not find such pattern. The two impulse response functions for series representing above and below median values of kurtosis are not meaningfully different from each other. This result suggests that kurtosis of price changes is not an important predictor of monetary non-neutrality in the data, and pricing models with sectoral heterogeneity should match the irrelevance of the moment.

Finally, we check the impulse response function for the ratio of the two prior moments, kurtosis over frequency. The last panel shows a similar pattern and ranking as the frequency split. For industries with a low value of kurtosis of price changes over frequency of price changes has a larger price response than those with high values. This is consistent with increased frequency driving less monetary non-neutrality and kurtosis having little or no effect. 
We now display impulse response functions to an identified monetary shock from the Romer and Romer policy shock series. This second method of constructing the impulse response function strongly supports our results from the FAVAR analysis. We examine the response to a one percent decrease in the realization of the policy measure. Results are shown in Figure 2. Consistent with the findings in Romer and Romer (2004), we find that monetary policy shocks begin to yield price responses with at least 24 months lag. We also observe the small "price puzzle" that is typically found using this measure.

First, consistent with our findings using FAVAR, we find that low price change frequency industries have a smaller price response to the monetary shock than the high frequency industries. This implies that they have a larger real output response. Only the price series with high frequency shows a meaningful response to monetary shocks after 30 months, while the series with low frequency series does not. In the second panel we see the impulse response when the industries are grouped by kurtosis of price changes. As we found in the FAVAR analysis, there is no significant difference in cumulative response of inflation to monetary policy shocks when observations are categorized based on kurtosis in the middle panel. In response to the expansionary monetary policy shock, price responses are observed after 35 quarters for the both high kurtosis price series and low kurtosis price series. This is contrary to the reactions of inflation when observations are categorized based on frequency and kurtosis over frequency. Similar results to the frequency grouping can be observed when price series are split based on kurtosis over frequency in the final panel.

\section{Model}

In this section we first demonstrate the inadequacy of micro pricing moments in determining monetary non-neutrality in a one sector menu cost model. We then fully specify a multi-sector pricing model that can match micro pricing facts as well as generate sectoral impulse responses to monetary shocks.

\section{A. One Sector Menu Cost Model}

This section uses a standard, second-generation menu cost model to study how pricing moments affect monetary non-neutrality. Firms can change prices by paying a menu cost 


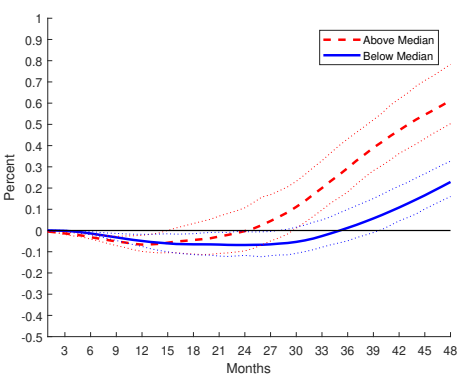

a Frequency

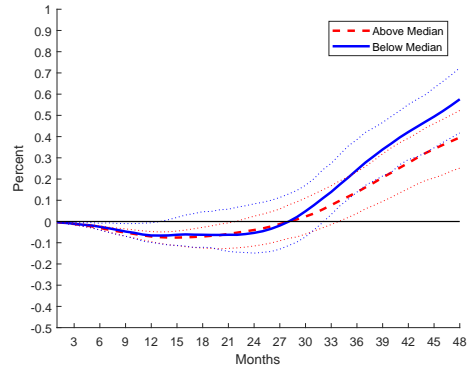

b Kurtosis

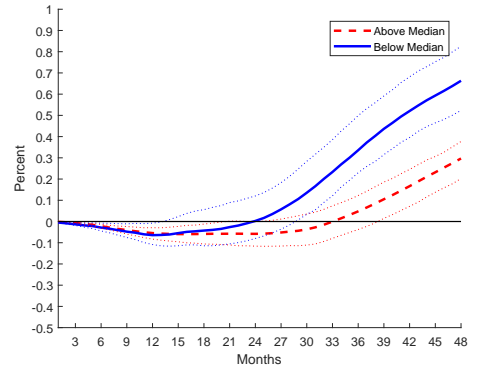

c Kurtosis/Frequency

Figure 2: Romer and Romer Monetary Policy Shock IRF

Note: In all three figures, "Above Median" and "Below Median" refer to the impulse response function of industries whose pricing moment is above or below the median value of that statistic for all industries. Estimated impulse responses of sectoral prices to a one percent decrease in the RR policy series are shown.

$\chi$, or with some small probability $\alpha$ they can change the price for free. Idiosyncratic productivity shocks arrive at rate $p_{z}$ with volatility $\sigma_{z}$ and persistence $\rho_{z}$. The firm productivity shock set up is the same as in Midrigan (2011).

The baseline model is calibrated to match price-setting statistics from the CPI micro data during the period 1988-2012 documented by Vavra (2014). ${ }^{7}$. We then undertake a comparative static exercise where we vary one pricing moment at a time to understand the importance of each for monetary non-neutrality. The moments we examine are price change frequency and kurtosis of price changes. This exercise also demonstrates if the ratio of kurtosis over frequency is a sufficient statistic for monetary non-neutrality in a simple menu cost model, or rather if it is a function of one of the underlying moments.

The five internally calibrated parameters that determine the price-setting moments are in Table 1 and the associated price-setting statistics are in Table 2. The model does a good job matching all the pricing moments from the data for the five calibrations we examine.

The table shows that we are able to vary one pricing moment at a time, while holding the others fixed. Monetary non-neutrality is measured by examining the impact of a one time permanent expansionary monetary shock on real output. The monetary shock increases nominal output by 0.002 , a one month doubling of the nominal output

\footnotetext{
${ }^{7}$ We define the fraction of small price changes as those less than $1 \%$ in absolute value and take this data from Luo and Villar (2015) This enables us to more directly compare small price changes across industries in the multi-sector analysis.
} 


\begin{tabular}{|c|c|c|c|c|c|}
\hline Parameter & Baseline & $\begin{array}{c}\text { High } \\
\text { Frequency }\end{array}$ & $\begin{array}{c}\text { Low } \\
\text { Frequency }\end{array}$ & $\begin{array}{c}\text { Low } \\
\text { Kurtosis }\end{array}$ & $\begin{array}{l}\text { Medium } \\
\text { Kurtosis }\end{array}$ \\
\hline$\chi$ & 0.0071 & 0.0033 & 0.0087 & 0.0107 & 0.0087 \\
\hline$p_{z}$ & 0.053 & 0.086 & 0.0652 & 0.076 & 0.0652 \\
\hline$\sigma_{z}$ & 0.16 & 0.173 & 0.147 & 0.126 & 0.147 \\
\hline$\rho_{z}$ & 0.65 & 0.98 & 0.78 & 0.75 & 0.78 \\
\hline$\alpha$ & 0.03 & 0.03 & 0.03 & 0.03 & 0.03 \\
\hline
\end{tabular}

Table 1: Model Parameters CPI Calibration

Note: The table shows the model parameters that are internally calibrated for each economy. $\chi$ denotes the menu cost of adjusting prices, $p_{z}$ the probability that log firm productivity follows an $\operatorname{AR}(1)$ process with standard deviation $\sigma_{z}, \rho_{z}$ the persistence of idiosyncratic probability shocks, and $\alpha$ is the probability of a free price change.

\begin{tabular}{|c|c|c|c|c|c|c|}
\hline Moment & Data & Baseline & $\begin{array}{c}\text { High } \\
\text { Frequency }\end{array}$ & $\begin{array}{c}\text { Low } \\
\text { Frequency }\end{array}$ & $\begin{array}{c}\text { Low } \\
\text { Kurtosis }\end{array}$ & $\begin{array}{l}\text { Medium } \\
\text { Kurtosis }\end{array}$ \\
\hline Frequency & 0.11 & 0.11 & 0.15 & 0.08 & 0.11 & 0.11 \\
\hline Fraction Up & 0.65 & 0.65 & 0.62 & 0.67 & 0.63 & 0.64 \\
\hline Average Size & 0.077 & 0.077 & 0.077 & 0.077 & 0.077 & 0.077 \\
\hline Fraction Small & 0.12 & 0.16 & 0.13 & 0.13 & 0.13 & 0.14 \\
\hline Kurtosis & 6.4 & 6.4 & 6.4 & 6.4 & 4.7 & 5.5 \\
\hline$\frac{\text { Kurtosis }}{\text { Frequency }}$ & 58.2 & 57.6 & 42.6 & 81.8 & 42.2 & 50.1 \\
\hline
\end{tabular}

Table 2: Frequency Comparative Static

Note: Monthly CPI data moments taken from Vavra (2014) and are calculated using data from 19882014. 


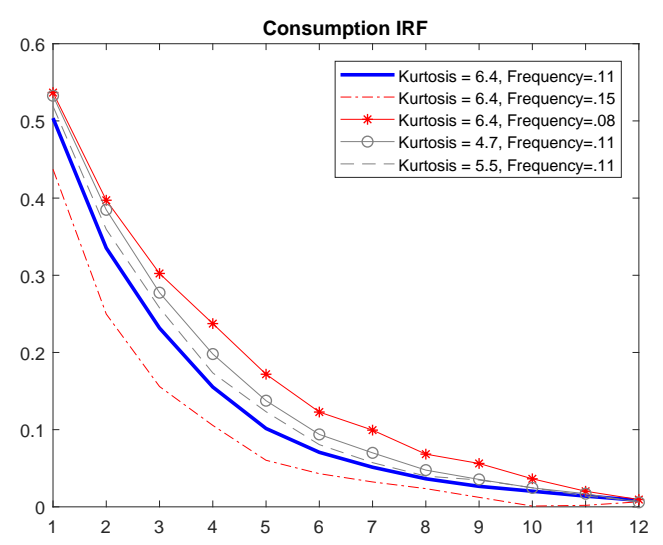

Figure 3: Consumption IRF Comparison

NoTE: Impulse response of output to a one time permanent increase in log nominal output of size 0.002 for different calibrations.

growth rate. The real effects of monetary shocks are then the cumulative consumption impact due to the shock. From Figure 3, the results confirm that monetary non-neutrality is a negative function of frequency in a menu cost model. The impulse response functions also show that as kurtosis of price changes decreases, it causes monetary non-neutrality to increase ${ }^{8}$.

The results also show that kurtosis over frequency does not make clear predictions for monetary non-neutrality. According to the sufficient statistic approach of Alvarez et al. (2016), the real output effect is completely determined by these two parameters. ${ }^{9}$ Yet the figure shows that varying frequency or kurtosis while holding the ratio constant delivers different cumulative consumption responses. This can be seen by comparing the high frequency and low kurtosis calibration. Increasing frequency and decreasing kurtosis both decrease the ratio, but they cause the total consumption response to move in opposite directions relative to the baseline calibration.

This stylized one sector model has shown that monetary non-neutrality does not have a one to one relationship with kurtosis of price changes and that the kurtosis over frequency ratio does not have a linear relationship with monetary non-neutrality. The frequency of price changes exhibits a strong negative relationship with monetary non-

\footnotetext{
${ }^{8}$ We repeat this exercise using the model of Midrigan (2011) who more explicitly models firm multiproduct pricing. We find the same relationship as in our model, that monetary non-neutrality falls as kurtosis increases while holding frequency of regular price changes constant.

${ }^{9} \mathrm{~A}$ key assumption to deliver this sufficiency result is the normality of cost shocks. Our quantitative model features leptokurtic productivity shocks such as in Midrigan (2011).
} 
neutrality.

\section{B. Multi-Sector Pricing Model}

This section now presents a multi-sector pricing model in order to demonstrate which price-setting models can replicate the ordering of impulse response functions. The quantitative pricing model nests both a second generation menu cost model as well as the Calvo pricing model. The multi-sector model follows Nakamura and Steinsson (2010) where there is some probability of a free Calvo price change and each sector has sector specific pricing behavior. It also includes leptokurtic idiosyncratic productivity shocks as in Midrigan (2011) as well as aggregate productivity shocks.

\section{B.1 Households}

A standard menu cost model of price-setting is now presented. The household side is standard. Households maximize current expected utility, given by

$$
E_{t} \sum_{\tau=0}^{\infty} \beta^{t}\left[\log \left(C_{t+\tau}\right)-\omega L_{t+\tau}\right]
$$

They consume a continuum of differentiated products indexed by i. The composite consumption good $C_{t}$ is the Dixit-Stiglitz aggregate of these differentiated goods,

$$
C_{t}=\left[\int_{0}^{1} c_{t}(z)^{\frac{\theta-1}{\theta}} d z\right]^{\frac{\theta}{\theta-1}}
$$

where $\theta$ is the elasticity of substitution between the differentiated goods.

Households decide each period how much to consume of each differentiated good. For any given level of spending in time t, households choose the consumption bundle that yields the highest level of the consumption index $C_{t}$. This implies that household demand for differentiated good $\mathrm{z}$ is

$$
c_{t}(z)=C_{t}\left(\frac{p_{t}(z)}{P_{t}}\right)^{-\theta}
$$

where $p_{t}(z)$ is the price of good $\mathrm{z}$ at time $\mathrm{t}$ and $P_{t}$ is the price level in period $\mathrm{t}$, calculated as 


$$
P_{t}=\left[\int_{0}^{1} p_{t}(z)^{1-\theta} d z\right]^{\frac{1}{1-\theta}}
$$

A complete set of Arrow-Debreu securities is traded, which implies that the budget constraint of the household is written as

$$
P_{t} C_{t}+E_{t}\left[D_{t, t+1} B_{t+1}\right] \leq B_{t}+W_{t} L_{t}+\int_{0}^{1} \pi_{t}(z) d z
$$

where $B_{t+1}$ is a random variable that denotes state contingent payoffs of the portfolio of financial assets purchased by the household in period $\mathrm{t}$ and sold in period $\mathrm{t}+1 . D_{t+1}$ is the unique stochastic discount factor that prices the payoffs, $W_{t}$ is the wage rate of the economy at time $\mathrm{t}, \pi_{t}(i)$ is the profit of firm $\mathrm{i}$ in period t. A no ponzi game condition is assumed so that household financial wealth is always large enough so that future income is high enough to avoid default.

The first order conditions of the household maximization problem are

$$
\begin{gathered}
D_{t, t+1}=\beta\left(\frac{C_{t} P_{t}}{C_{t+1} P_{t+1}}\right) \\
\frac{W_{t}}{P_{t}}=\omega C_{t}
\end{gathered}
$$

where equation (23) describes the relationship between asset prices and consumption, and (24) describes labor supply.

\section{B.2 Firms}

In the model there are a continuum of firms indexed by $\mathrm{i}$ and industry $\mathrm{j}$. The production function of firm $i$ is given by

$$
y_{t}(i)=A_{t} z_{t}(i) L_{t}(i)
$$

where $L_{t}(i)$ is labor rented from households. $A_{t}$ are aggregate productivity shocks and $z_{t}(i)$ are idiosyncratic productivity shocks.

Firm i maximizes the present discounted value of future profits 


$$
E_{t} \sum_{\tau=0}^{\infty} D_{t, t+\tau} \pi_{t+\tau}(i)
$$

where profits are given by:

$$
\pi_{t}(i)=p_{t}(i) y_{t}(i)-W_{t} L_{t}(i)-\chi_{j}(i) W_{t} I_{t}(i)
$$

$I_{t}(i)$ is an indicator function equal to one if the firm changes its price and equal to zero otherwise. $\chi_{j}(i)$ is the sector specific menu cost. The final term indicates that firms must hire an extra $\chi_{j}(i)$ units of labor if they decide to change prices with probability $1-\alpha_{j}$, or may change their price for free with probability $\alpha_{j} .{ }^{10}$ This is the "CalvoPlus" parameter from Nakamura and Steinsson (2010) that enables the model to encapsulate both a menu cost as well as a pure Calvo model. In the menu cost model this parameter is set such that a small probability of receiving a free price change enables the model to generate small price changes, while in the Calvo model set up it is calibrated to the frequency of price changes with an infinite menu cost.

Total demand for good $i$ is given by:

$$
y_{t}(i)=Y_{t}\left(\frac{p_{t}(i)}{P_{t}}\right)^{-\theta}
$$

The firm problem is to maximize profits in (27) subject to its production function (25), demand for its final good product (28), and the behavior of aggregate variables.

Aggregate productivity follows an $\mathrm{AR}(1)$ process:

$$
\log \left(A_{t}\right)=\rho_{A} \log \left(A_{t-1}\right)+\sigma_{A} \nu_{t}
$$

where $\nu_{t} \sim \mathrm{N}(0,1)$

The log of firm productivity follows a mean reverting process with leptokurtic shocks:

$$
\log z_{t}(i)= \begin{cases}\rho_{z} \log z_{t-1}(i)+\sigma_{z, j} \epsilon_{t}(i) & \text { with probability } p_{z, j} \\ \log z_{t-1}(i) & \text { with probability } 1-p_{z, j}\end{cases}
$$

where $\epsilon_{t}(i) \sim \mathrm{N}(0,1)$.

Nominal aggregate spending follows a random walk with drift:

\footnotetext{
${ }^{10}$ This is a reduced form modeling device representing multiproduct firms like in Midrigan (2011).
} 


$$
\log \left(S_{t}\right)=\mu+\log \left(S_{t-1}\right)+\sigma_{s} \eta_{t}
$$

where $S_{t}=P_{t} C_{t}$ and $\eta_{t} \sim \mathrm{N}(0,1)$.

The state space of the firms problem is an infinite dimensional object because the evolution of the aggregate price level depends on the joint distribution of all firms' prices, productivity levels, and menu costs. It is assumed that firms only perceive the evolution of the price level as a function of a small number of moments of the distribution as in Krusell and Smith (1998). In particular, we assume that firms use a forecasting rule of the form:

$$
\log \left(\frac{P_{t}}{S_{t}}\right)=\gamma_{0}+\gamma_{1} \log A_{t}+\gamma_{2} \log \left(\frac{P_{t-1}}{S_{t}}\right)+\gamma_{3}\left(\log \left(\frac{P_{t-1}}{S_{t}}\right) * \log A_{t}\right)
$$

The accuracy of the rule is checked using the maximum Den Haan (2010) statistic in a dynamic forecast. The model is solved recursively by discretization and simulated using the non-stochastic simulation method of Young (2010).

\section{B.3 Calibration}

For the model discrimination exercise we have a set of parameters common to all sectors. The discount rate is set to $\beta=(0.96)^{\frac{1}{12}}$ as the model is monthly. The elasticity of substitution is set to $\theta=4$ as in Nakamura and Steinsson (2010). ${ }^{11}$ The nominal shock process is calibrated to match the mean growth rate of nominal GDP minus the mean growth rate of real GDP and the standard deviation of nominal GDP growth over the period of 1998 to 2012. This implies $\mu=0.002$ and $\sigma_{s}=0.0037$. Finally the model is linear in labor so we calibrate the productivity parameters to match the quarterly persistence and standard deviation of average labor productivity from 1976-2005. This gives $\rho_{A}=0.8925$ and $\sigma_{A}=0.0037$.

The second set of parameters is calibrated internally to match micro pricing moments. These are the menu cost $\chi_{j}$, the probability of an idiosyncratic shock, $p_{z, j}$, the volatility of idiosyncratic shocks $\sigma_{j}$, and the probability of a free price change $\alpha_{j}$. For all models

\footnotetext{
${ }^{11}$ While other papers in the literature set the elasticity of substitution to higher numbers such as 7 in Golosov and Lucas (2007), this lowers the average mark up, but the ordered price level response to a monetary shock would not change.
} 
evaluated we use two sectors to match our baseline empirical results.

\section{Results}

This section now presents our main model results. We first show that a multi-sector menu cost model that matches micro pricing moments is unable to match the ordering of impulse response functions for all slices of the data. In particular, it predicts differences in response when sectors are split by kurtosis, contradicting the empirical results. However, we show a multi-sector Calvo model consistent with micro pricing data is able to match all impulse response function orderings. Lastly, we do a comparative static exercise where we vary sectoral parameters to show that a menu cost model can match the irrelevance of kurtosis for impulse response functions. However, this comes at the cost of missing micro price moments.

We calibrate the two sector model to match three different cuts of the data: frequency, kurtosis, and kurtosis over frequency. For each of the parameterizations we calculate the price-setting moments for each industry, then calibrate each sector to the average price-setting moments above or below the median statistic of interest. Price-setting moments for all calibrations are in Table 3. In the menu cost calibration we are matching frequency of price changes, average size of price changes, fraction of small price changes, and kurtosis of price changes for each sector. These four moments pin down four sector specific parameters. The parameters are the menu cost $\chi_{j}$, the probability of an idiosyncratic productivity shock $p_{z, j}$, volatility of idiosyncratic productivity shocks $\sigma_{z, j}$, and the probability of a free price change $\alpha_{j}$. The parameter values are shown in Table 4. In the Calvo variation of the model, price changes are fully time dependent, so we set the menu cost to infinity and no longer target the fraction of small price changes. This leaves three parameters to target frequency, average size, and kurtosis of price changes.

The average price-setting moments across sectors show large differences in the moment of interest, yet surprisingly minor differences in other moments. In the frequency data cut, the low frequency of price changes is 0.14 while the high frequency of price changes is 0.35 . Yet, the kurtosis of price changes is 6.2 and 6.7 respectively, which enables the model to demonstrate how a change in frequency impacts monetary non-neutrality. The kurtosis data cut also exhibits a similar pattern when the average kurtosis across the 


\begin{tabular}{|c|c|c|c|c|c|c|}
\hline \multicolumn{7}{|c|}{ Frequency Calibration } \\
\hline \multirow[b]{3}{*}{ Moment } & \multirow{2}{*}{\multicolumn{3}{|c|}{$\begin{array}{c}\text { Low Frequency } \\
\text { Sector }\end{array}$}} & \multirow{2}{*}{\multicolumn{3}{|c|}{$\begin{array}{c}\text { High Frequency } \\
\text { Sector }\end{array}$}} \\
\hline & & & & & & \\
\hline & Data & $\mathrm{MC}$ & Calvo & Data & $\mathrm{MC}$ & Calvo \\
\hline Frequency & 0.14 & 0.14 & 0.14 & 0.35 & 0.35 & 0.34 \\
\hline Average Size & 0.073 & 0.074 & 0.071 & 0.062 & 0.061 & 0.060 \\
\hline Fraction Small & 0.46 & 0.32 & 0.35 & 0.31 & 0.42 & 0.49 \\
\hline Kurtosis & 6.2 & 6.1 & 6.4 & 6.7 & 6.7 & 6.9 \\
\hline$\frac{\text { Kurtosis }}{\text { Frequency }}$ & 44.8 & 42.8 & 46.2 & 19.3 & 18.8 & 20.1 \\
\hline \multicolumn{7}{|c|}{ Kurtosis Calibration } \\
\hline & \multicolumn{3}{|c|}{$\begin{array}{l}\text { Low Kurtosis } \\
\quad \text { Sector }\end{array}$} & \multicolumn{3}{|c|}{$\begin{array}{l}\text { High Kurtosis } \\
\text { Sector }\end{array}$} \\
\hline Moment & Data & $\mathrm{MC}$ & Calvo & Data & $\mathrm{MC}$ & Calvo \\
\hline Frequency & 0.24 & 0.24 & 0.23 & 0.25 & 0.25 & 0.25 \\
\hline Average Size & 0.072 & 0.071 & 0.071 & 0.063 & 0.070 & 0.062 \\
\hline Fraction Small & 0.35 & 0.35 & 0.26 & 0.42 & 0.44 & 0.51 \\
\hline Kurtosis & 4.0 & 4.0 & 4.1 & 9.0 & 8.2 & 9.2 \\
\hline$\frac{\text { Kurtosis }}{\text { Frequency }}$ & 17.0 & 16.9 & 17.6 & 36.0 & 32.3 & 37.5 \\
\hline \multicolumn{7}{|c|}{ Kurtosis/Frequency Calibration } \\
\hline & \multicolumn{3}{|c|}{$\begin{array}{c}\text { Low Kurtosis/Frequency } \\
\text { Sector }\end{array}$} & \multicolumn{3}{|c|}{$\begin{array}{c}\text { High Kurtosis/Frequency } \\
\text { Sector }\end{array}$} \\
\hline Moment & Data & $\mathrm{MC}$ & Calvo & Data & $\mathrm{MC}$ & Calvo \\
\hline Frequency & 0.30 & 0.28 & 0.30 & 0.18 & 0.20 & 0.18 \\
\hline Average Size & 0.067 & 0.069 & 0.065 & 0.068 & 0.065 & 0.068 \\
\hline Fraction Small & 0.32 & 0.34 & 0.37 & 0.45 & 0.42 & 0.45 \\
\hline Kurtosis & 4.7 & 4.6 & 4.9 & 8.3 & 8.2 & 8.5 \\
\hline$\frac{\text { Kurtosis }}{\text { Frequency }}$ & 15.7 & 16.3 & 16.3 & 45.0 & 40.0 & 47.2 \\
\hline
\end{tabular}

Table 3: Multi-sector Pricing Moments

NotE: Monthly pricing moments calculated using PPI data from 1998-2005. For all calibrations, each pricing moment is calculated at the 6 digit NAICS level. The average pricing moment is then calculated for industries above and below the median statistic of interest. Fraction small is the fraction of price changes less than one percent in absolute value. The MC column denotes the menu cost model calibration and the Calvo column denotes the Calvo model calibration. 


\begin{tabular}{|c|c|c|c|c|}
\hline \multicolumn{5}{|c|}{ Frequency Calibration } \\
\hline \multirow[b]{3}{*}{ Parameter } & \multirow{2}{*}{\multicolumn{2}{|c|}{$\begin{array}{c}\text { Low Frequency } \\
\text { Sector }\end{array}$}} & \multirow{2}{*}{\multicolumn{2}{|c|}{$\begin{array}{c}\text { High Frequency } \\
\text { Sector }\end{array}$}} \\
\hline & & & & \\
\hline & $\mathrm{MC}$ & Calvo & $\mathrm{MC}$ & Calvo \\
\hline$\chi_{j}$ & 0.052 & $\infty$ & 0.00047 & $\infty$ \\
\hline$p_{z, j}$ & 0.073 & 0.139 & 0.16 & 0.244 \\
\hline$\sigma_{z, j}$ & 0.167 & 0.15 & 0.141 & 0.136 \\
\hline$\alpha_{j}$ & 0.11 & 0.139 & 0.22 & 0.348 \\
\hline \multicolumn{5}{|c|}{ Kurtosis Calibration } \\
\hline \multirow[b]{3}{*}{ Parameter } & \multirow{2}{*}{\multicolumn{2}{|c|}{$\begin{array}{l}\text { Low Kurtosis } \\
\text { Sector }\end{array}$}} & \multirow{2}{*}{\multicolumn{2}{|c|}{$\begin{array}{l}\text { High Kurtosis } \\
\text { Sector }\end{array}$}} \\
\hline & & & & \\
\hline & $\mathrm{MC}$ & Calvo & $\mathrm{MC}$ & Calvo \\
\hline$\chi_{j}$ & 0.109 & $\infty$ & 0.001 & $\infty$ \\
\hline$p_{z, j}$ & 0.254 & 0.56 & 0.10 & 0.12 \\
\hline$\sigma_{z, j}$ & 0.10 & 0.11 & 0.21 & 0.185 \\
\hline$\alpha_{j}$ & 0.212 & 0.236 & 0.138 & 0.25 \\
\hline \multicolumn{5}{|c|}{ Kurtosis/Frequency Calibration } \\
\hline \multirow[b]{3}{*}{ Parameter } & \multirow{2}{*}{\multicolumn{2}{|c|}{$\begin{array}{c}\text { Low Kurtosis/Frequency } \\
\text { Sector }\end{array}$}} & \multirow{2}{*}{\multicolumn{2}{|c|}{$\begin{array}{c}\text { High Kurtosis/Frequency } \\
\text { Sector }\end{array}$}} \\
\hline & & & & \\
\hline & $\mathrm{MC}$ & Calvo & $\mathrm{MC}$ & Calvo \\
\hline$\chi_{j}$ & 0.0021 & $\infty$ & 0.012 & $\infty$ \\
\hline$p_{z, j}$ & 0.183 & 0.425 & 0.08 & 0.104 \\
\hline$\sigma_{z, j}$ & 0.115 & 0.108 & 0.205 & 0.188 \\
\hline$\alpha_{j}$ & 0.175 & 0.301 & 0.17 & 0.183 \\
\hline
\end{tabular}

Table 4: Multi-sector Model Calibration

NotE: The table shows the model parameters that are internally calibrated for each economy where the sector is indexed by j. $\chi_{j}$ denotes the menu cost of adjusting prices, $p_{z, j}$ the probability that $\log$ firm productivity follows an $\operatorname{AR}(1)$ process with standard deviation $\sigma_{z, j}$, and $\alpha_{j}$ is the probability of a free price change. The MC column denotes the menu cost model calibration and the Calvo column denotes the Calvo model calibration. 
low and high sectors varies by 4.0 to 9.0 , while frequency is only differs by one percent per month. The kurtosis over frequency split exhibits large differences in both frequency and kurtosis, where the two pricing moments work together to generate the low and high response respectively.

In our model discrimination exercise, we ask if each model is capable of replicating the ordering of the empirical impulse response to a monetary shock. In each model we simulate the effects of an expansionary monetary shock. Log nominal output has a permanent increase of 0.002 and we trace out the effects to the price level. ${ }^{12}$ The results are in Figure 4. In the top left panel, we show the price response relative to trend in the menu cost model when the data are cut by frequency of price changes. As expected, the high frequency of price changes sector incorporates more of the monetary shock to prices on impact and more quickly fully integrates the shock into the price level. These results are consistent with the FAVAR and narrative evidence.

The price level impulse responses from the menu cost model where we slice the data by kurtosis of price changes are in the top center panel. The panel shows a substantial difference in impulse response functions. The high kurtosis sector has a larger price response to a monetary shock and therefore a smaller consumption response. This model, while consistent with the micro pricing moments, is inconsistent with the empirical impulse response evidence. In both the FAVAR and narrative evidence, when the data is ordered by kurtosis there is no difference in the average response. This evidence suggests that kurtosis of price changes is not informative for monetary non-neutrality. ${ }^{13}$

The top right panel shows the impulse response when the data are cut by kurtosis over frequency. Consistent with Alvarez et al. (2016), the sector with high kurtosis over frequency has a smaller price response and therefore has a larger consumption response to a monetary shock.

We now show that a Calvo model is able to match the ordering of impulse responses in all three cuts of the data. The bottom left panel in Figure 4 shows that a high frequency

\footnotetext{
${ }^{12}$ We choose the size of the shock to match a one month doubling of the nominal output growth rate. In the menu cost model the size of the nominal shock will affect the fraction of price adjusters and thus have implications for the impulse response function, while in the Calvo model the size of the shock does not impact non-neutrality.

${ }^{13}$ While kurtosis does not have effects on the ordering of the price response to a monetary shock, it can be informative for discriminating among models. Any model that gives a prediction for monetary non-neutrality should be consistent with kurtosis of price changes not affecting the price response to a monetary shock.
} 
sector has a larger price response. The middle panel shows that the Calvo model can also match the irrelevance of kurtosis. The distance between the impulse response functions is small relative to all other orderings. Lastly, the bottom right panel shows the Calvo model when the sectors are split by kurtosis over frequency. The model replicates the larger price response of the low kurtosis over frequency sector, and therefore the smaller consumption response.

These models have different implications for monetary non-neutrality. Consistent with prior evidence, all three Calvo model calibrations have greater monetary nonneutrality, as measured by the cumulative output response to a monetary shock, compared to all three menu cost model calibrations. In both the Calvo and menu cost models, the frequency calibration has greater monetary non-neutrality than the other two calibrations. This suggests that sectors with the lowest frequency have outsize influence on monetary non-neutrality in the aggregate, consistent with the argument made in Nakamura and Steinsson (2010).

While the menu cost model does not match irrelevance of kurtosis in the impulse responses, it is possible to parameterize it to do so. But this comes at the cost of missing the micro price moments. We show this using a comparative static exercise. We start this exercise from the baseline multi-sector menu cost parameterization based on the kurtosis of price changes. Then we take one sectoral parameter at a time in the set $\Theta \in\left(\chi_{j}, \sigma_{z, j}, p_{z, j}, \alpha_{j}\right)$, and vary it while holding all other parameters constant. The parameter is indexed by industry $\mathrm{j}$, allowing us to vary one sector parameter while holding the other constant. The search of parameters is done within the values of the two baseline parameters.

The empirical impulse response function for kurtosis of price changes does not differ. We search for the set of parameters that minimizes the sum of squared deviation in the price level impulse response to a monetary shock between the two sectors, low and high kurtosis. The search shows that the two parameters that decrease the distance between the responses the most are the volatility of idiosyncratic shocks and the menu cost. However the menu cost parameter allows us to decrease distance between responses the most, when the low kurtosis sector has a high menu cost consistent with the baseline specification and the high kurtosis sector needs to increase the menu cost relative to the baseline specification, while all other parameter values are set to their original value. The 


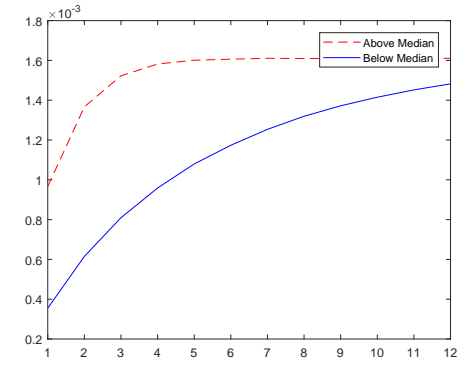

a Frequency MC

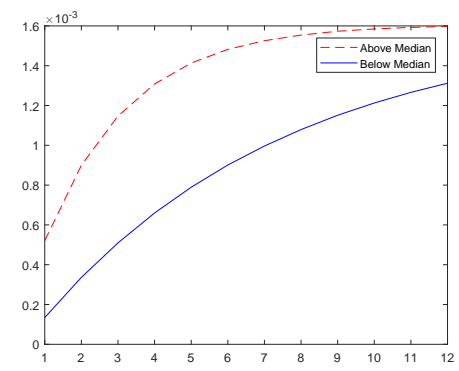

d Frequency Calvo

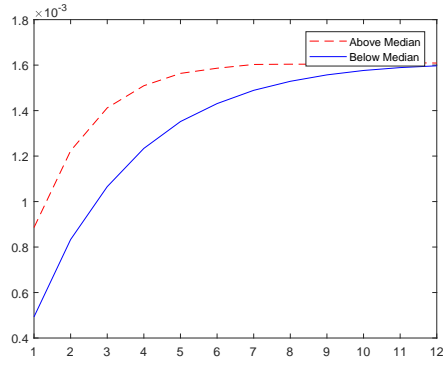

b Kurtosis MC

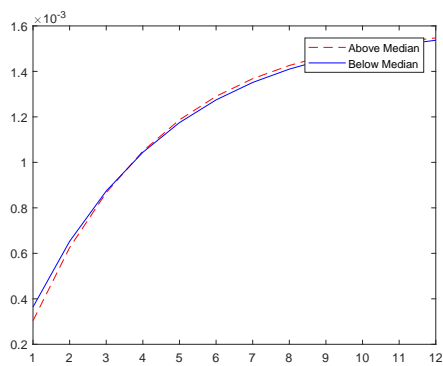

e Kurtosis Calvo

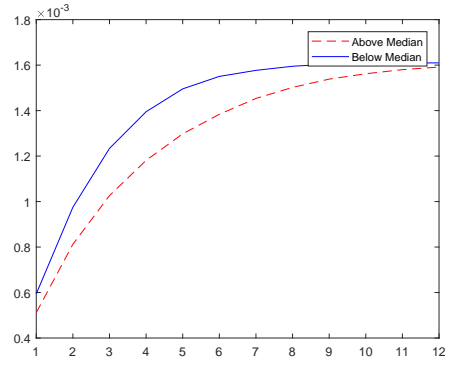

c Kurtosis/Frequency MC

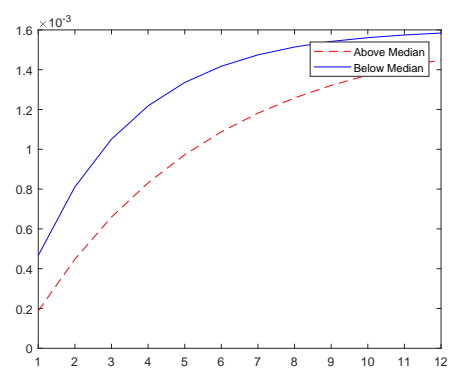

f Kurtosis/Frequency Calvo

Figure 4: Multi-sector Model Monetary Policy Shock IRF

Note: In all six figures, "Above Median" and "Below Median" refer to the impulse response function of the sector calibrated to match the pricing moments above or below the median value of the statistic for all industries. The top row shows the menu cost model results and the bottom row shows the Calvo model results. Model calibration noted under each figure. Impulse responses of sectoral prices in response to a permanent increase in money. 


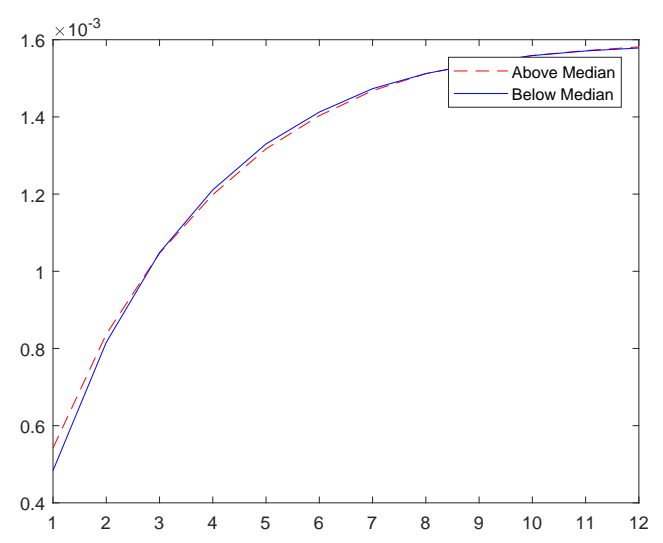

Figure 5: Comparative Static Exercise - MC Model Kurtosis Irrelevance

Note: The above figure shows a two sector menu cost model that is calibrated to match the above and below median pricing statistics when the data are cut by kurtosis. Each sector's menu cost are then changed until the impulse response functions are nearly identical.

impulse response associated with the minimum distance occurs when $\chi_{1}=0.109$ and $\chi_{2}=0.008$, and all other parameters are fixed at their baseline calibration. The impulse response functions are shown in Figure 5. The figure shows that it is possible to have no difference in impulse response when we have heterogeneous sectors. Yet this comes at the cost of missing the micro pricing moments for the high kurtosis sector. In particular, both the frequency of price changes as well as kurtosis need to be decreased for the second sector to match the two impulses. The associated moments are shown in Table 5.

This section shows that our new methodology can discriminate among different pricing models. A menu cost model is not able to fit all micro moments as well as match the sectoral price response to a monetary shock when calibrated to match above and below-median kurtosis sectors. Yet, a Calvo model is able to match the impulse response ordering in all three calibrations of the model. While this is not evidence that the Calvo model is the correct micro-foundation for price stickiness, it shows that when studying the effects of monetary shocks on pricing behavior it fits the empirically implied response better. Our exercise further demonstrates that the menu cost model needs an additional feature to fit the key variable response of interest to monetary shocks and therefore be useful for policy analysis. 


\begin{tabular}{|c|c|c|c|c|c|c|}
\hline \multicolumn{7}{|c|}{ Kurtosis Calibration } \\
\hline \multirow[b]{3}{*}{ Moment } & \multicolumn{3}{|c|}{$\begin{array}{l}\text { Low Kurtosis } \\
\text { Sector }\end{array}$} & \multicolumn{3}{|c|}{$\begin{array}{l}\text { High Kurtosis } \\
\text { Sector }\end{array}$} \\
\hline & & & mparat & & & Comparative \\
\hline & Data & Baseline & Static & Data & Baseline & Static \\
\hline Frequency & 0.24 & 0.24 & 0.24 & 0.25 & 0.25 & 0.20 \\
\hline Average Size & 0.072 & 0.071 & 0.071 & 0.063 & 0.070 & 0.084 \\
\hline Fraction Small & 0.35 & 0.35 & 0.34 & 0.42 & 0.44 & 0.35 \\
\hline Kurtosis & 4.0 & 4.0 & 4.0 & 9.0 & 8.2 & 6.4 \\
\hline$\frac{\text { Kurtosis }}{\text { Frequency }}$ & 17.0 & 16.9 & 16.8 & 36.0 & 32.3 & 32.3 \\
\hline
\end{tabular}

Table 5: Kurtosis Comparative Static Pricing Moments

NotE: The above table shows the pricing moments generated for the comparative static exercise. Monthly pricing moments calculated using PPI data from 1998-2005. Each pricing moment is calculated at the 6 digit NAICS level. The average pricing moment is then calculated for industries above and below the median statistic of interest. Fraction small is the fraction of price changes less than one percent in absolute value. Comparative Static column shows the pricing moments for a counterfactual economy where kurtosis of price changes generates irrelevance in the impulse response functions.

\section{Conclusion}

We have proposed a new methodology to discriminate among models that uses both micro and macro moments to discipline model choice. The key insight of our method lies in tying the use of macro moments to discipline the response of the main variable of interest following a key policy shock to the simultaneous choice of micro moments that pin down model behavior. Some of these micro moments may be sufficient statistics.

To demonstrate the power of our method, we apply it to discriminate among leading pricing models that are widely used in policy making, Calvo and menu cost. First, we show empirically that a lower frequency of price changes is related to larger consumption responses to monetary policy shocks. Kurtosis is not an empirically sufficient statistic for the real effects of monetary shocks, but as a derivative, kurtosis over frequency is. Both Calvo and menu cost models match key micro price moments and the impulse response ordering if we consider frequency and kurtosis over frequency as moments. However, only Calvo replicates the irrelevance of kurtosis. In a menu cost model, kurtosis is not a sufficient statistic for monetary non-neutrality by itself, and kurtosis over frequency is not sufficient unless it has a one-to-one relationship with frequency. Our menu cost model can match the irrelevance of kurtosis, but at the cost of missing key micro price moments.

Future work might consider quantitative refinements of the second step of our 
methodology for our application. Currently, the second step consists of a non-parametric comparison of impulse response orderings in models and the data. An extension in our application would also match the particular shapes of impulse response functions. Such an exercise would require adding a number of features to the model to replicate inertial and hump-shaped behavior of aggregate inflation and quantities, as stressed by Christiano et al. (2005). 


\section{References}

Alvarez, F., M. Beraja, M. Gonzalez-Rozada, and P. A. Neumeyer (2019). From hyperinflation to stable prices: Argentina's evidence on menu cost models. The Quarterly Journal of Economics 134(1), 451-505.

Alvarez, F., H. Le Bihan, and F. Lippi (2016, October). The real effects of monetary shocks in sticky price models: A sufficient statistic approach. American Economic Review 106 (10), 2817-51.

Bachmann, R., R. Caballero, and E. M. R. A. Engel (2013). Aggregate implications of lumpy investment: New evidence and a dsge model. American Economic Journal: Macroeconomics 5(4), 29-67.

Berger, D., R. Caballero, and E. Engel (2018). Missing Aggregate Dynamics and VAR Approximations of Lumpy Adjustment Models. Working papers, Northwestern University, Department of Economics.

Bernanke, B. S., J. Boivin, and P. Eliasz (2005). Measuring the effects of monetary policy: A factor-augmented vector autoregressive (favar) approach. The Quarterly Journal of Economics 120(1), 387-422.

Boivin, J., M. P. Giannoni, and I. Mihov (2009, March). Sticky prices and monetary policy: Evidence from disaggregated us data. American Economic Review 99(1), 350-84.

Christiano, L. J., M. Eichenbaum, and C. L. Evans (2005). Nominal rigidities and the dynamic effects of a shock to monetary policy. Journal of Political Economy 113(1), $1-45$.

Cravino, J., T. Lan, and A. A. Levchenko (2018, June). Price stickiness along the income distribution and the effects of monetary policy. CEPR Discussion Papers 12967, C.E.P.R. Discussion Papers.

Dotsey, M. and A. L. Wolman (2018, July). Inflation and Real Activity with Firm Level Productivity Shocks. Working Papers 18-19, Federal Reserve Bank of Philadelphia.

Eichenbaum, M. (2018a). Modern dsge models: Theory and evidence. Presentation, https://youtu.be/Wgboaq9_Kx4 min. 9.46' - 10.58', Nobel Symposium, Swedish House of Finance.

Eichenbaum, M. (2018b). Modern dsge models: Theory and evidence. Discussion, https://youtu.be/69rLdiWRoUs min. 23.39' -24.31', Nobel Symposium, Swedish House of Finance.

Gagnon, E. (2009). Price setting during low and high inflation: Evidence from mexico. The Quarterly Journal of Economics 124(3), 1221-1263.

Golosov, M. and R. Lucas (2007). Menu costs and phillips curves. Journal of Political Economy 115(2), 171-199.

Gourieroux, C., A. Monfort, and E. Renault (1993). Indirect inference. Journal of Applied Econometrics, 85-118.

Haan, W. J. D. (2010). Assessing the accuracy of the aggregate law of motion in models with heterogeneous agents. Journal of Economic Dynamics and Control 34(1), 79 99. Computational Suite of Models with Heterogeneous Agents: Incomplete Markets and Aggregate Uncertainty. 
Karadi, P. and A. Reiff (2018). Menu costs, aggregate fluctuations, and large shocks. Technical report, Forthcoming, AEJ: Macroeconomics.

Khan, A. and J. K. Thomas (2008). Idiosyncratic shocks and the role of nonconvexities in plant and aggregate investment dyanmics. Econometrica 76 (2), 395-436.

Kim, S. (2016). Quality, price stickiness, and monetary policy. Working paper, Brandeis University.

Klenow, P. J. and B. A. Malin (2011). Chapter 6 - Microeconomic Evidence on PriceSetting. Volume 3 of Handbook of Monetary Economics, pp. 231 - 284. Elsevier.

Luo, S. and D. Villar (2015). The skewness of the price change distribution: A new touchstone for sticky price models. FEDS Working Paper 2017-028, Board of Governors of the Federal Reserve System, Finance and Economics Discussion Series.

McFadden, D. (1989). A method of simulated moments for estimation of discrete response models without numerical integration. Econometrica 57(5), 995-1026.

Midrigan, V. (2011). Menu costs, multiproduct firms, and aggregate fluctuations. Econometrica 79(4), 1139-1180.

Nakamura, E. and J. Steinsson (2010). Monetary non-neutrality in a multi-sector menu cost model. Quarterly Journal of Economics 125(3), 961-1013.

Nakamura, E., J. Steinsson, P. Sun, and D. Villar (2018). The elusive costs of inflation: Price dispersion during the u.s. great inflation. The Quarterly Journal of Economics 133(4), 1933-1980.

Romer, C. D. and D. H. Romer (2004). A new measure of monetary shocks: Derivation and implications. American Economic Review 94(4), 1055-1084.

Romer, D. H. and C. D. Romer (2000, June). Federal reserve information and the behavior of interest rates. American Economic Review 90(3), 429-457.

Smith, J. A. (1993). Estimating Nonlinear Time-series Models Using Simulated Vector Autoregressions, Volume 8.

Vavra, J. (2014). Inflation dynamics and time-varying volatility: New evidence and an Ss interpretation. The Quarterly Journal of Economics 129(1), 215-258.

Young, E. R. (2010). Solving the incomplete markets model with aggregate uncertainty using the krusell-smith algorithm and non-stochastic simulations. Journal of Economic Dynamics and Control 34(1), $36-41$. 


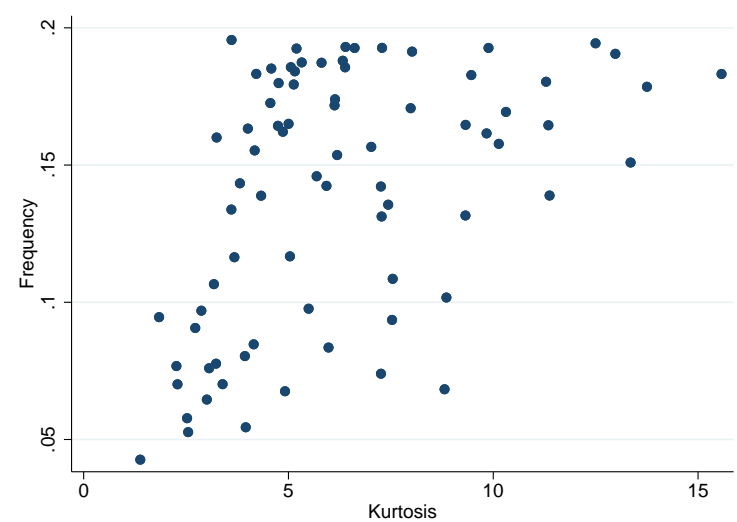

a Low Frequency Sectors

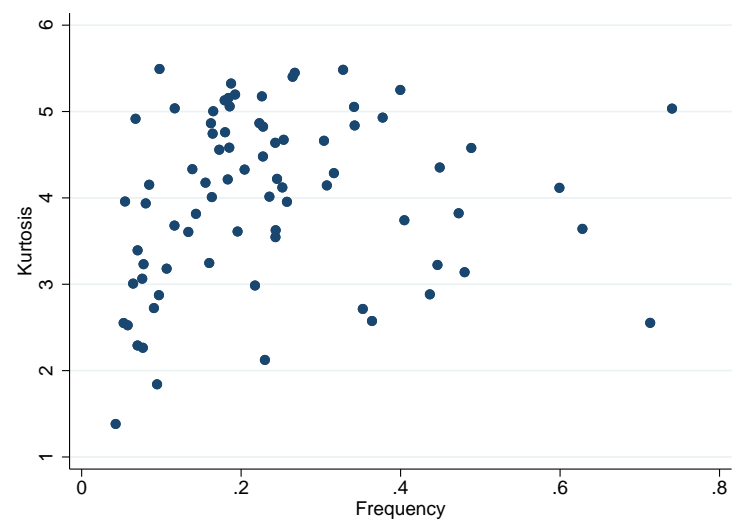

c Low Kurtosis Sectors

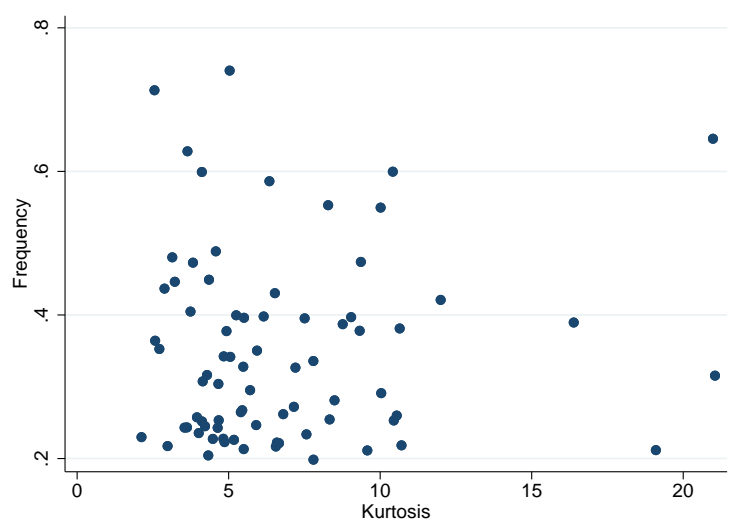

b High Frequency Sectors

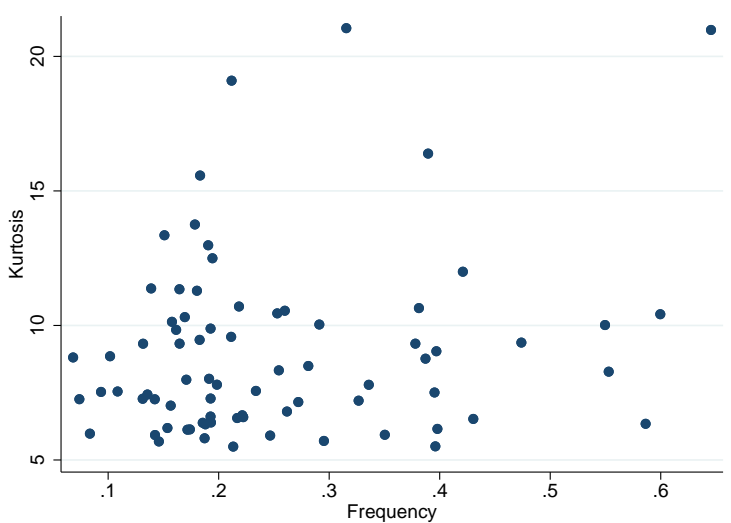

d High Kurtosis Sectors

Figure 6: Comparative Static Exercise

Note: The figures above plot average industry price setting statistics by group. Panels a and b in the top row plot kurtosis against frequency for the sectors with above-median and below-median frequency. Panels $\mathrm{c}$ and $\mathrm{d}$ in the bottom row plot frequency against kurtosis for the sectors with above-median and below-median kurtosis.

\section{A Appendix}

\section{A. Sectoral Characteristics}

We plot the 154 industry level price setting moments in figure 6 when the industries are separated into above- and below-median values of a moment of interest. These results show the heterogeneity in price setting moment across industries to compare to the average values in table 3 .

Table 3 shows the average kurtosis values are 6.2 and 6.7 for the low and high frequency sectors respectively. The top row of figure 6 shows there is not a strong 
relationship between kurtosis and frequency for the high frequency group, while the low frequency sectors exhibit a positive relationship between frequency and kurtosis.

In the bottom row the industries are split into above- and below-median kurtosis values. The industries below-median kurtosis show a positive relationship between kurtosis and frequency, while industries with above-median do not show a positive relationship.

\section{B. Two-Sector Comparative Static Results}

This section shows the full comparative static results. The goal of this exercise was to find if the multi-sector menu cost model can match the irrelevance of kurtosis. We do this by varying one sectoral parameter at a time while holding all other parameters constant. For example, we change the value of $\alpha$ for the low kurtosis sector, while holding all other parameters in both sectors fixed, then change the value of $\alpha$ for the high kurtosis sector while holding all parameters fixed. The parameter set we search over is $\Theta \in$ $\left(\chi_{j}, \sigma_{z, j}, p_{z, j}, \alpha_{j}\right)$.

For each parameter, we search the space that is between the original calibrated values for the two sectors. Our criterion function is to minimize the sum of squared deviations of the price levels of the two sectors following a monetary shock. Full results of this exercise are in figure 7.

The results indicate that the menu cost and idiosyncratic volatility parameters are most able to generate irrelevance of kurtosis for monetary non-neutrality. Specifically when the menu cost for the low kurtosis sector is set to $\chi_{1}=0.109$, the value from the baseline calibration, the distance between the two impulses shrinks as the high kurtosis sector menu cost increases from it's baseline value. The minimum value is when $\chi_{2}=$ 0.008. In this parameterization, the frequency as well as the kurtosis of price changes decreases. This shows that it is possible to match the empirical irrelevance of kurtosis in the impulse response to a monetary shock, but at the cost of matching potentially relevant micro pricing moments. 


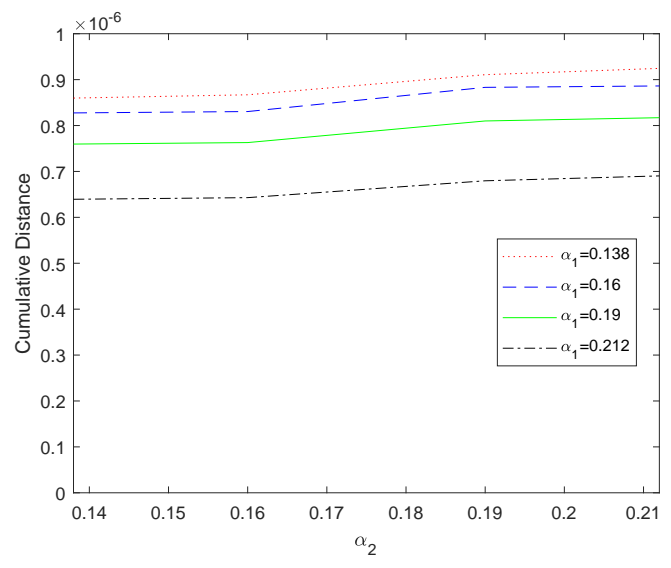

a Calvo Plus Probability - $\alpha$

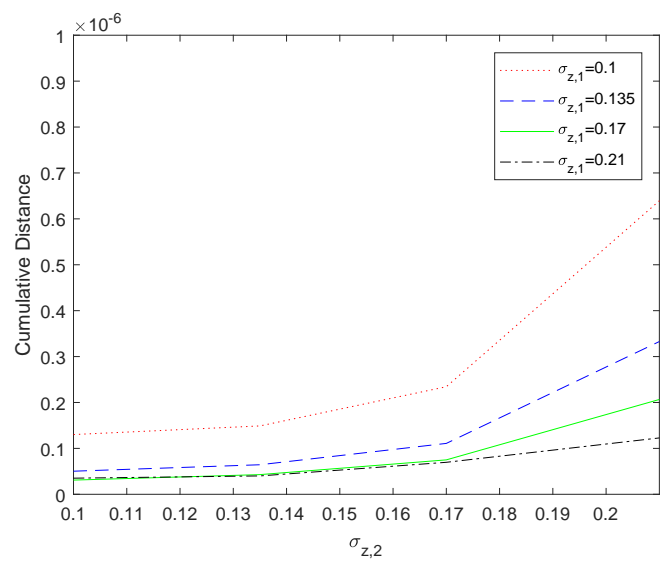

c Idiosyncratic Volatility $-\sigma_{z}$

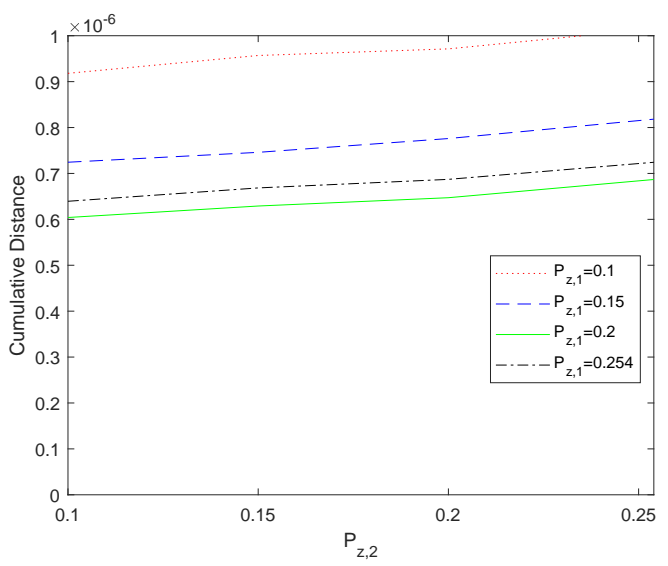

b Probability of Shock $-P_{z}$

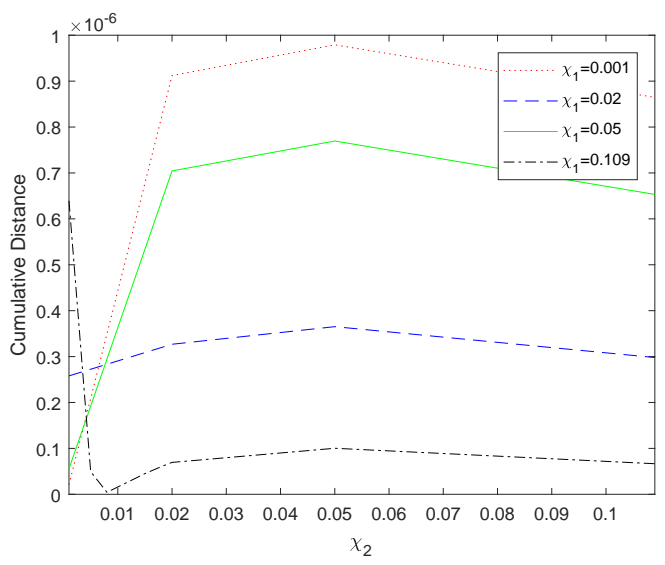

d Menu Cost - $\chi$

Figure 7: Comparative Static Exercise

Note: Cumulative distance between price impulse responses shown as each parameter value varies. Cumulative distance between impulse responses is defined as $\sum_{t=1}^{T=12}\left(P_{t, 1}-P_{t, 2}\right)^{2}$, where $\mathrm{t}$ is indexing months after a positive monetary shock. The $\mathrm{x}$-axis denotes the parameter value for the high kurtosis sector, while each line indicates a different value of the parameter for the low kurtosis sector. Each panel varies one parameter at a time. 